\title{
The Effect of Liquid Medium on Silicon Grinding and Oxidation during Wet Grinding Process
}

\author{
Woo Teck Kwon, Soo Ryong Kim, Young Hee Kim, Yoon Joo Lee, Dong Geun Shin, Ji Yeon Won, \\ and Sea Cheon $\mathrm{Oh}^{*}{ }^{\dagger}$
}

Energy \& Environmental Division, Korea Institute of Ceramic Engineering \& Technology, Seoul 153-801 Korea

*Department of Environmental Engineering, Kongju National University, Chungnam-Do 314-701, Korea

(Received February 9, 2014; Revised March 6, 2014; Accepted March 7, 2014)

\section{습식분쇄공정에서 액상매체가 실리콘 분쇄 및 산화특성에 미치는 영향

\author{
권우택 · 김수룡 · 김영희 · 이윤주 · 신동근 · 원지연 · 오세천*† \\ 한국세라믹기술원 에너지환경소재본부 \\ *공주대학교 환경공학과
} \\ (2014년 2월 9일 접수 ; 2014년 3월 6일 수정 ; 2014년 3월 7일 채택)}

\begin{abstract}
The influence of a liquid medium duringa wet-milling process in the grinding and oxidation of silicon powder was investigated. Distilled water, dehydrated ethanol and diethylene glycol were used as the liquid media. The applied grinding times were $0.5,3$, and $12 \mathrm{~h}$. Ground silicon powder samples were characterized by means of aparticle size analysis, scanning electron microscopy(SEM), $\mathrm{x}-$ ray powder diffraction (XRD), FT-IR spectroscopy and by a chemical composition analysis. From the results of the characterization process, we found that diethylene glycol is the most efficient liquid medium when silicon powder is ground using a wet-milling process. The FT-IR results show that the Si-O band intensity in an unground silicon powder is quite strongbecause oxygen becomes incorporated with silicon to form $\mathrm{SiO}_{2}$ in air. By applying deionized water as a liquid medium for the grinding of silicon, the $\mathrm{SiO}_{2}$ content increased from $4.12 \%$ to $31.7 \%$. However, in the cases of dehydrated ethanol and diethylene glycol, it was found that the $\mathrm{SiO}_{2}$ contents after grinding only changed insignificantly, from $4.12 \%$ to $5.91 \%$ and $5.28 \%$, respectively.
\end{abstract}

Key words : Grinding, Liquid medium, Silicon, Oxidation, Silicon oxide

\section{1. 서 론}

분쇄는 본질적으로 입자의 표면적을 형성하기 위하여 기존의 물리, 화학적 결합을 파괴하는 것을 의미하는 것 으로, 입자의 표면에너지를 감소시키면 응집과 파괴된 표 면의 재결합이 방지되어 분쇄효율이 향상된다. 분쇄공정 은 시멘트, 안료, 세라믹뿐만 아니라 의학, 환경 및 에너 지산업 등에 광범위하게 적용되고 있으나 분쇄공정에 있 어서 실제 분쇄에 사용되는 에너지는 전체 투입에너지의 극히 일부에 불과한 것으로 보고되어 있어 분쇄효율을 향 상시키기 위한 연구가 지속되고 있다. ${ }^{1,2)}$

액상매체의 유무에 따라서 습식과 건식분쇄로 구분되

${ }^{\dagger}$ Corresponding author : Sea Cheon Oh

E-mail : ohsec@kongju.ac.kr

Tel : +82-41-521-9423 Fax : +82-41-552-0380
며 일반적으로 습식분쇄가 건식분쇄 방법에 비하여 효율 적이다. ${ }^{3)}$ 습식분쇄에서 물을 액상매체로 사용하는 경우에 는 분쇄물의 표면과 물 분자의 화학반응에 의하여 표면 에너지가 감소한다. ${ }^{2}$ 또한 습식분쇄에서는 위에 언급한 표면에너지 감소뿐만 아니라 분쇄과정에서 분쇄매체 표 면에 붙어있는 미분과 조분 사이의 완충작용을 감소시키 는 효과도 작용하는 것으로 알려져 있다. 습식분쇄의 액 상매체 종류에 대한 연구에 있어서는 유기물 액상매체가 물보다 효율적이라는 보고가 있다. ${ }^{2)}$ 예를 들면 Engelhardt 는 석영의 분쇄에 있어서 알코올을 액상매체로 사용할 경 우에 물을 사용했을 경우와 비교해서 동일한 비표면적을 발현하는데 훨씬 적은 에너지를 필요로 한다는 연구결과 를 발표했다. 또한 Ziegler는 에틸렌글리콜, 프로필렌글리 콜 및 트리에탄올아민과 같은 유기물 액상매체를 사용하 였을 경우에 물을 사용했을 경우와 비교해서 시멘트 분 쇄물의 생산량이 $40 \%$ 증가하는 것으로 보고했다. 많은 
연구자의 연구결과에서와 같이 분쇄공정은 다량의 에너 지가 요구되는 보편적인 공정으로서 사용하는 액상매체 의 종류에 의해서 분쇄효율 및 표면에너지 변화가 크게 나타남을 알 수 있다.

실리콘은 다양한 종류의 세라믹 원료로 사용되고 있다. 실리콘의 표면원자는 많은 불포화 결합으로 인하여 매우 불안정한 상태가 되고, 공기 및 수용액 조건에서 쉽게 산 화되어 $\mathrm{SiO}_{2}$ 로 전환된다. ${ }^{4,5)}$ 최근 들어 반도체 및 태양광 산업에서 대량 발생하고 있는 실리콘 부산물의 활용이 요 구되고 있으며, 이러한 실리콘의 활용을 위해서는 실리콘 표면산화 및 $\mathrm{SiO}_{2}$ 로의 전환특성을 파악하는 것이 중요하 다. 또한 사용용도에 맞는 전처리 및 가공공정이 요구되 며 분쇄공정은 이러한 공정에서 요구되는 기본공정이라 고 할 수 있다. 지금까지 태양광 산업의 실리콘웨이퍼 생 산과 관련해서 액상매체 종류에 따른 실리콘 웨이퍼 표 면의 산화특성에 대한 연구는 있었으나 실리콘 분말의 분 쇄과정에서 액상매체 종류에 따른 실리콘 분쇄 및 산화 특성 변화에 대한 연구는 거의 없었다. 따라서 본 연구에 서는 실리콘의 활용을 위한 전처리 과정으로서 습식분쇄 공정에서 실리콘 분말의 분쇄 및 산화특성에 미치는 액 상매체의 영향을 살펴보고자 하였다.

\section{2. 실험 방법}

시중에서 유통되고 있는 고순도 실리콘 분말 ( $\mathrm{Si} 95.9 \%$, $\mathrm{SiO}_{2} 4.12 \%$, 평균입경 $6.1 \mu \mathrm{m}, \mathrm{ACM}$ 사, 대한민국)을 원료 로 사용하였다. 사용한 원료의 입도분포 및 $\mathrm{SEM}$ 측정결 과를 Fig. 1에 나타내었다. 분쇄용기로 $500 \mathrm{ml}$ 용량의 플 라스틱 통을 사용하였으며, 분쇄매체로 순도 $99 \%$ 이상의 탄화규소 볼을 이용하였다. 실험을 위해서 플라스틱 통에 탄화규소 볼을 크기 별 $(0.5 \mathrm{~mm}, 1.0 \mathrm{~mm}$ 및 $5.0 \mathrm{~mm})$ 로 전 체 플라스틱 통의 $30 \%$ 가 되도록 충전한 후 실리콘을 $110 \mathrm{~g}$ 을 채워 넣었다. 이때 탄화규소 볼 충전량은 총 $870 \mathrm{~g}$ 이며 $0.5 \mathrm{~mm} 200 \mathrm{~g}, 1.0 \mathrm{~mm} 370 \mathrm{~g}, 5.0 \mathrm{~mm} 300 \mathrm{~g}$ 을 충전 하였다. 플라스틱 통에 실리콘과 탄화규소 볼을 충전하고 난 후에 전체 부피의 $45 \%$ 가 되도록 액상매체를 충전하 였다. 액상매체는 실험실 증류장치 (IWD-2000S, 삼보과 학)에서 제조한 증류수와 무수에탄올 $(99.9 \%$, Carlo Erba Reagents사) 및 디에틸렌글리콜 $(99.0 \%$, 대정화금)을 종류 별로 사용하였다. 분쇄된 실리콘 분말의 형상관찰은 주사 전자현미경 (Scanning Electron Microscopy, SEM: S-4100, $\mathrm{HITACHI})$ 을 이용하였으며, 입도분석은 입도분석기 (Mastersizer S Ver. 2.15, Malvern)를 이용하여 분석하였다. 실리콘 분쇄에 따른 산화특성 변화를 살펴보기 위해서 $\mathrm{SiO}_{2}$ 와 실리콘 성분분석을 실시하였다. $\mathrm{SiO}_{2}$ 성분은 알루 미노실리케이트 내화물의 화학분석방법 (KS L ISO 21587-1) 을 이용하였으며, 실리콘 성분분석은 파인세라믹용 탄화

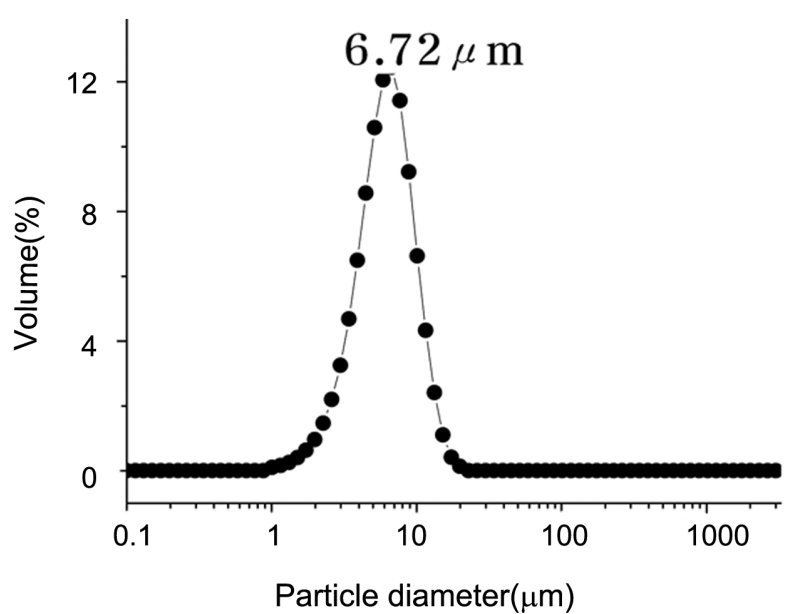

(a)

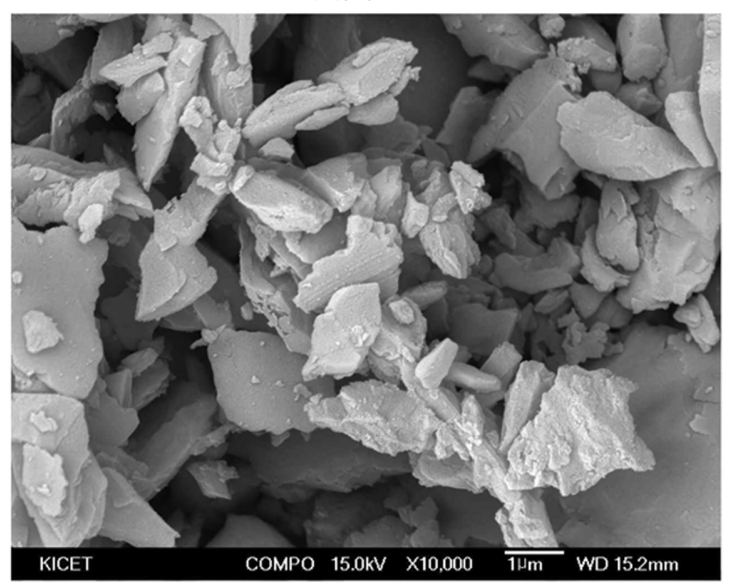

(b)

Fig. 1. Characterization analysis results of silicon powder (a) particle size distribution and (b) SEM image.

규소 분말의 화학분석방법 (KSL 1612)을 이용하여 측정 하였다. 분쇄물의 결정상 분석은 XRD (P/MAX 2200V/ $\mathrm{PC}$, Rigaku Corp.)를 사용하였다. 액상매체 변화에 따른 실리콘 입자의 표면 산화특성 변화를 살펴보기 위해서 FT-IR (FT/IR-460 plus, JASCO) 분석을 실시하였다.

\section{3. 결과 및 고찰}

습식분쇄과정에서 액상매체 종류에 따른 실리콘 입자 의 입자크기 및 형상관찰을 위한 SEM 분석결과를 Fig. 2 에 나타내었다. SEM 분석결과, 분쇄시간이 $0.5 \mathrm{~h}, 3 \mathrm{~h}, 12 \mathrm{~h}$ 진행될수록 입자크기가 점차 작아짐을 알 수 있었다. 액 상매체 종류에 따른 분쇄거동을 비교한 결과, 증류수를 액상매체로 사용할 경우에는 무수에탄올과 디에틸렌글리 콜을 사용한 경우와 비교해서 조대한 입자가 상대적으로 많이 관찰되며, $0.5 \mu \mathrm{m}$ 이하의 미세한 입자가 조대한 입 자의 표면에 부착되어 있는 것을 알 수 있다. 분쇄과정에 


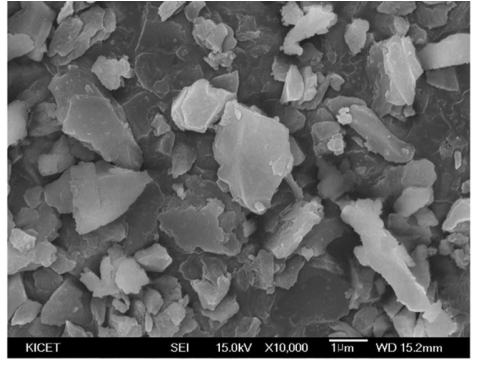

(a) $0.5 \mathrm{~h}$

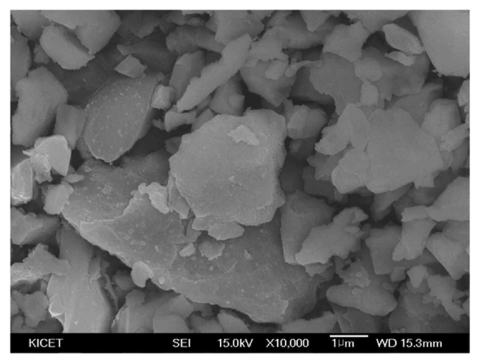

(b) $0.5 \mathrm{~h}$

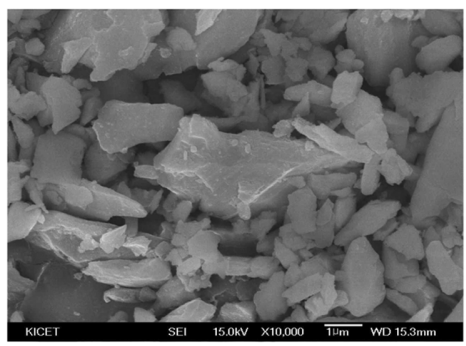

(c) $0.5 \mathrm{~h}$

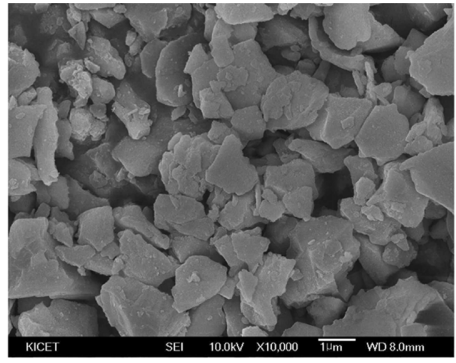

(a) $3 \mathrm{~h}$

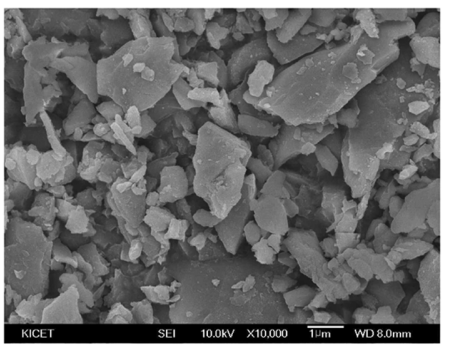

(b) $3 \mathrm{~h}$

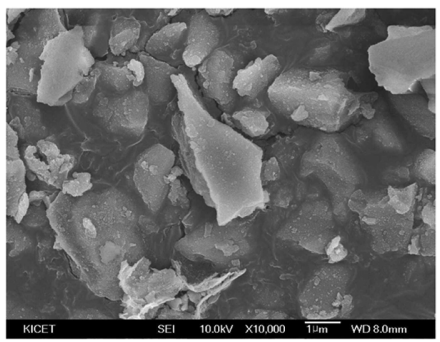

(c) $3 \mathrm{~h}$

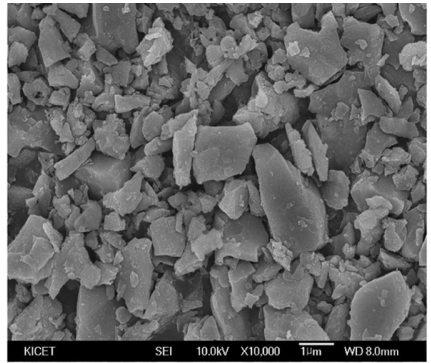

(a) $12 \mathrm{~h}$

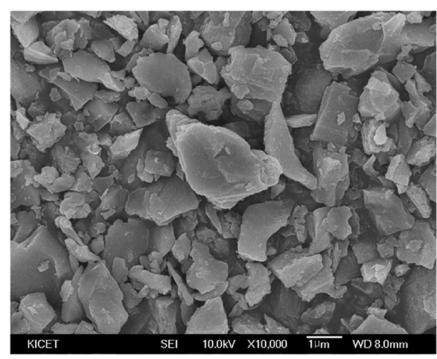

(b) $12 \mathrm{~h}$

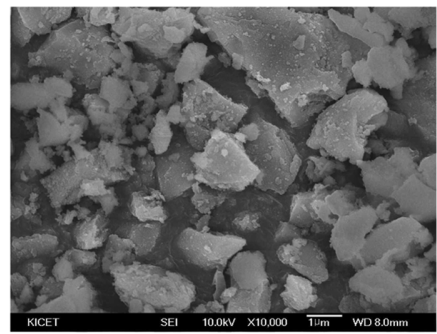

(c) $12 \mathrm{~h}$

Fig. 2. SEM images of silicon powder varying with liquid medium ((a) diethylene glycol, (b) anhydrous ethanol, and (c) de-ionized water) and grinding time ( $0.5 \mathrm{~h}, 3 \mathrm{~h}$, and $12 \mathrm{~h})$.

서 입자의 표면에너지를 감소시켜서 입자의 응집과 파괴 된 표면의 재결합이 방지될수록 분쇄효율이 증가하는 것(6) 으로 알려져 있다. 따라서 증류수를 액상매체로 사용한 경우에는 조대한 입자표면에 미세한 입자가 상대적으로 많이 부착되어 있는 것으로 관찰되어 분쇄효율에 영향을 미칠 것으로 판단되었다.

액상매체 종류 및 분쇄시간 변화에 따른 실리콘 분말 의 입도변화를 입도분석기를 이용하여 측정하였으며 실 리콘의 평균입도 변화를 Fig. 3에 나타내었다. 디에틸렌 글리콜을 액상매체로 이용했을 경우에 30 분 분쇄조건에 서 평균입도가 $6.1 \mu \mathrm{m}$ 에서 $3.9 \mu \mathrm{m}$ 로 감소하였는데, 이것 은 무수에탄올과 증류수를 사용했을 때 $5.0 \mu \mathrm{m}$ 와 $4.5 \mu \mathrm{m}$ 로 감소한 것과 비교해볼 때 디에틸렌글리콜을 액상매체 로 사용하는 것이 실리콘분쇄에 효율적임을 보여준다. 이 러한 경향은 3 시간과 12 시간 분쇄조건에서도 나타남을 알 수 있다. 분쇄시간 변화에 따른 입도 분석결과, 분쇄 초 반 30 분까지는 비교적 효율적으로 분쇄가 진행되지만 3

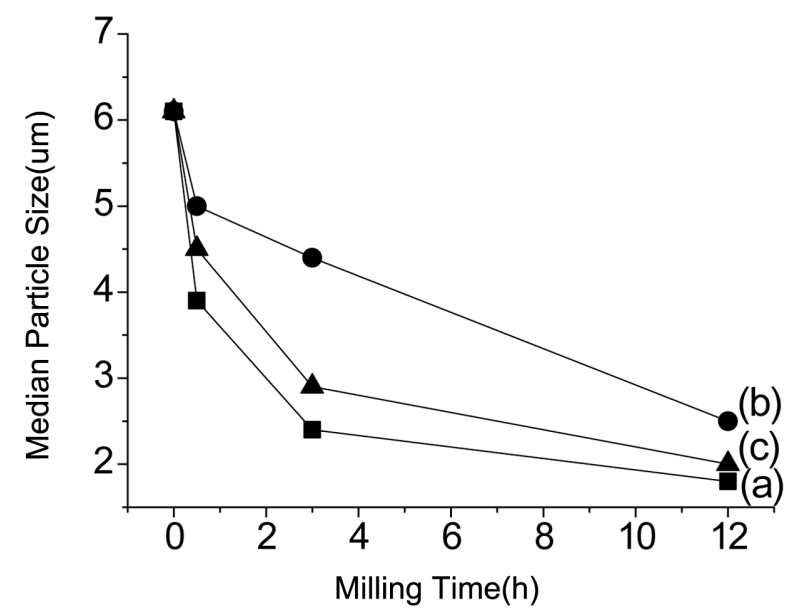

Fig. 3. Median particle size of silicon powder varying with liquid medium ((a) diethylene glycol, (b) anhydrous ethanol, and (c) de-ionized water) and grinding time (0.5 h, $3 \mathrm{~h}$, and $12 \mathrm{~h}$ ). 
시간, 12 시간 진행될수록 분쇄효율이 저하됨을 알 수 있 다. 특히 무수에탄올과 증류수를 액상매체로 사용할 경우 에는 12 시간 분쇄조건에서도 실리콘 분말의 평균입도가 각 각 $2.5 \mu \mathrm{m}$ 와 $2.0 \mu \mathrm{m}$ 로 크게 나타나 미립자 분쇄에 한 계가 있음을 알 수 있었다. 일반적으로 분쇄는 충격과 마 모과정에 의해서 이루어지며, 충격은 커다란 입자 분쇄에 효율적이고 마모는 작은 입자를 미립화하는데 효율적이 다. 분쇄과정에서 충격효과를 높이는 것은 커다란 볼이 효율적이며, 마모효과를 높이는 것은 작은 볼이 효율적인 것으로 알려져 있다. 따라서 실리콘 분말을 $2 \mu \mathrm{m}$ 이하의 작은 크기로 분쇄하기 위해서는 작은 크기의 볼을 증대 하는 방향으로 볼 배열을 조절하는 것이 필요할 것으로 판단된다. 분쇄효율은 분쇄물의 표면에너지와 밀접한 관 련이 있으며 액상매체는 분쇄물의 표면에너지에 영향을 주는 것으로 보고하고 있다. ${ }^{1-3)}$ 이러한 선행 연구결과로 부터, 본 실험에서 디에틸렌글리콜을 액상매체로 사용하 는 것이 실리콘분쇄에 가장 효율적이었던 실험결과는 분 쇄과정에서 실리콘 입자의 표면에너지변화와 밀접한 연 관이 있을 것이라 판단된다.

분쇄시간 및 분쇄매체 변화에 따른 XRD 분석결과를 Fig. 4에 나타내었다. XRD 분석결과에서 알 수 있듯이 실 리콘 피크가 관찰되며, 분쇄시간이 0.5 시간, 3 시간, 12 시 간으로 증가할수록 실리콘 피크 강도가 감소함을 알 수 있다. Ibrahim은 분쇄시간은 분쇄물의 결정구조와 밀접한 연관이 있는 것으로 보고하고 있으며) 이러한 기존의 연 구결과에 비추어볼 때 분쇄시간을 증가할수록 실리콘의 결정구조가 변형되어 결정성이 저하되는 것을 알 수 있 다. 액상매체 종류에 따라서 분쇄효율 차이가 발생함에도 불구하고 XRD 피크 강도 변화는 크지 않은데, 분쇄효율 은 액상매체와 실리콘 입자간의 표면에너지와 밀접한 관 련이 있으며 실리콘입자의 결정구조에 미치는 영향은 크 지 않기 때문인 것으로 판단된다.

실리콘 분쇄에 따른 산화특성 변화를 살펴보기 위해서 $\mathrm{SiO}_{2}$ 와 실리콘 성분분석을 실시하였으며 Table 1에 분석 결과를 나타내었다. $\mathrm{SiO}_{2}$ 와 실리콘 성분 분석결과, 분쇄 시간이 증가할수록 실리콘 함량은 감소하며 $\mathrm{SiO}_{2}$ 함량은 상대적으로 증가함을 알 수 있다. 특히 증류수를 액상매 체로 사용할 경우에 분쇄시간을 3 시간, 12 시간 진행함에 따라서 $\mathrm{SiO}_{2}$ 함량은 $4.12 \%$ 에서 각 각 $20.9 \%$ 와 $31.7 \%$ 로 크게 증가함을 알 수 있다. 하지만 무수에탄올과 디에틸 렌글리콜을 사용할 경우에는 12 시간 분쇄했을 경우에도 $\mathrm{SiO}_{2}$ 함량이 $4.12 \%$ 에서 각 각 $5.91 \%$ 와 $5.28 \%$ 로 적게 나 타나 분쇄에 따른 산화진행을 최소화 할 수 있음을 알 수 있었다. 증류수를 사용할 경우에 실리콘의 산화가 급격히 증가하는 것은 실리콘 표면의 불포화 결합으로 인해서 불 안정하게 되고 특히 공기 및 수용액 조건에서 쉽게 산화 된다는 기존의 연구결과와 일치함을 알 수 있다., ${ }^{5,89}$

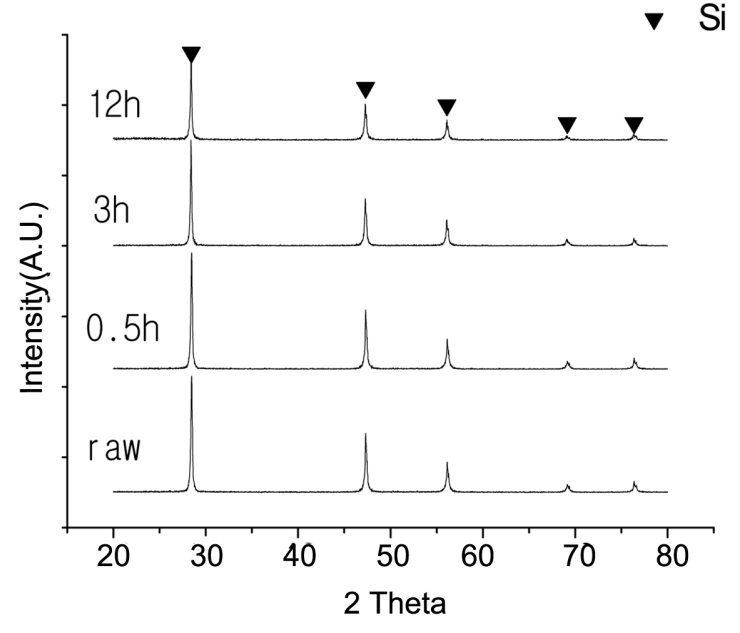

(a) Diethylene glycol

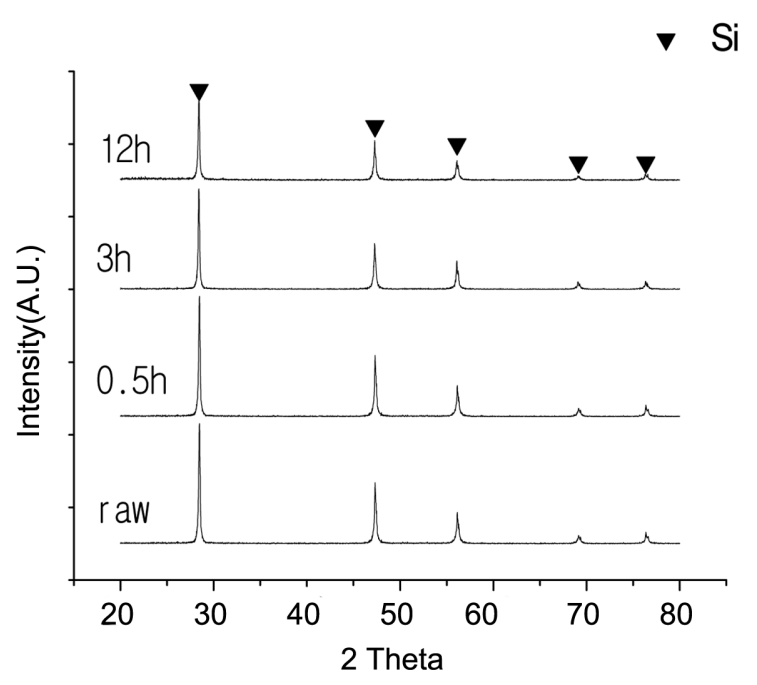

(b) Anhydrous ethanol

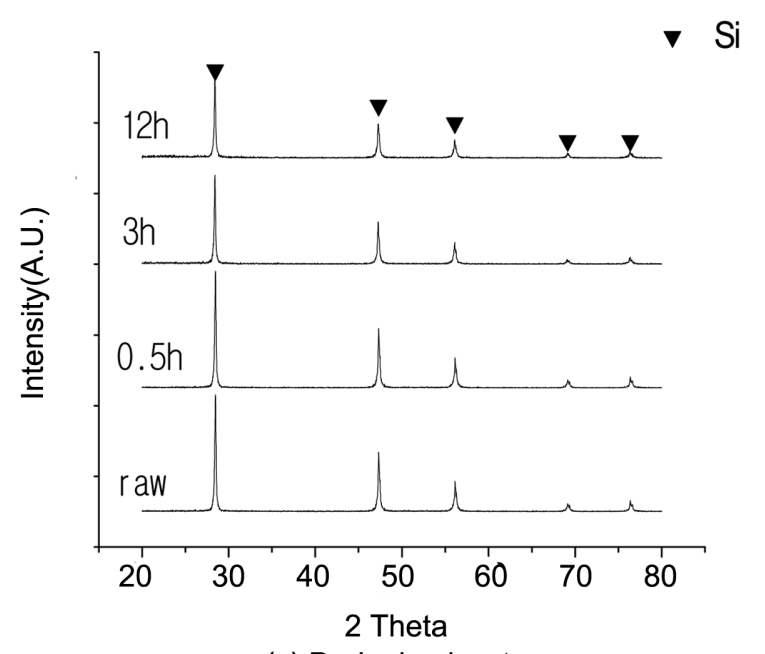

(c) De-ionized water

Fig. 4. XRD peaks of silicon powder varying with liquid medium and grinding time in wet-milling process. 
Table 1. The Variation of $\mathrm{Si} / \mathrm{SiO}_{2}$ Contents of the Silicon Powder with Applying of Liquid Medium in a Wet-milling Process

\begin{tabular}{cccc}
\hline \multirow{2}{*}{ Liquid medium } & $\begin{array}{c}\text { Milling time } \\
(\mathrm{h})\end{array}$ & \multicolumn{2}{c}{$\begin{array}{c}\text { Chemical composition } \\
\text { (\%) }\end{array}$} \\
\cline { 3 - 4 } & & $\mathrm{Si}$ & $\mathrm{SiO}_{2}$ \\
\hline Silicon powder & Raw material) & 95.9 & 4.12 \\
Diethylene & 3 & 95.6 & 4.42 \\
glycol & 12 & 94.7 & 5.28 \\
Anhydrous & 3 & 95.8 & 4.21 \\
ethanol & 12 & 94.1 & 5.91 \\
De-ionized & 3 & 95.6 & 20.9 \\
water & 12 & 68.3 & 31.7 \\
\hline
\end{tabular}

액상매체 종류 및 분쇄시간별로 분쇄한 시료의 FT-IR 분석결과를 Fig. 5에 나타내었다. FT-IR 분석결과, 분쇄하 기 전의 실리콘 원료분말의 $\mathrm{Si}-\mathrm{O}$ 피크가 가장 크고, 분쇄 시간이 증가할수록 $\mathrm{Si}-\mathrm{H}$ 피크가 증가하는 반면에 $\mathrm{Si}-\mathrm{O}$ 피 크 강도가 감소함을 알 수 있다. 이 결과는 실리콘 원료 분말의 표면이 산화가 가장 많이 진행된 것을 의미하는 것으로 실리콘 분말 표면의 불완전성으로 인하여 실리콘 이 공기중의 산소와 쉽게 결합한 것으로 판단된다. 액상 매체 변화에 따른 FT-IR 측정결과, 디에틸렌글리콜을 사 용했을 경우에 분쇄가 0.5 시간, 3 시간, 12 시간 진행될수록 $\mathrm{Si}-\mathrm{H}$ 피크는 증가하는 반면에 $\mathrm{Si}-\mathrm{O}$ 피크는 점차적으로 감 소하는 경향을 나타냈다. 무수에탄올과 증류수를 액상매 체로 사용했을 경우에는 분쇄가 진행될수록 $\mathrm{Si}-\mathrm{H}$ 피크는 증가하지만 $\mathrm{Si}-\mathrm{O}$ 피크변화는 크지 않았다. 분쇄과정에 따 른 실리콘 입자의 산화특성은 입자표면의 산화와 밀접한 관련이 있으며, 이런 관점에서 볼 때 분쇄가 진행될수록 $\mathrm{Si}-\mathrm{O}$ 피크가 점차적으로 감소한 디에틸렌글리콜이 실리 콘 입자표면 산화방지에 가장 효과적일 것으로 판단되었다.

\section{4. 결 론}

습식분쇄과정에서 액상매체 변화가 실리콘 분쇄 및 산 화특성에 미치는 영향을 살펴보았다. 액상매체로 디에틸 렌글리콜을 사용할 경우에 무수에탄올과 증류수를 사용 할 때와 비교해서 실리콘 입자가 작게 분쇄되어 실리콘 분쇄에 효율적이었다. 분쇄가 진행될수록 실리콘이 산화 되어 $\mathrm{SiO}_{2}$ 로 전환되는 것을 확인하였다. 특히 증류수를 액상매체로 사용할 경우에 $\mathrm{SiO}_{2}$ 함량이 급격히 증가하여 실리콘의 산화가 촉진됨을 알 수 있었다. 하지만 무수에 탄올과 디에틸렌글리콜을 사용할 경우에는 분쇄진행에 따 른 $\mathrm{SiO}_{2}$ 함량 증가가 적게 나타나 실리콘의 산화진행을 최소화 할 수 있었다. FT-IR 분석결과, 실리콘 원료분말 의 $\mathrm{Si}-\mathrm{O}$ 피크가 가장 크게 나타나 실리콘 분말의 표면산

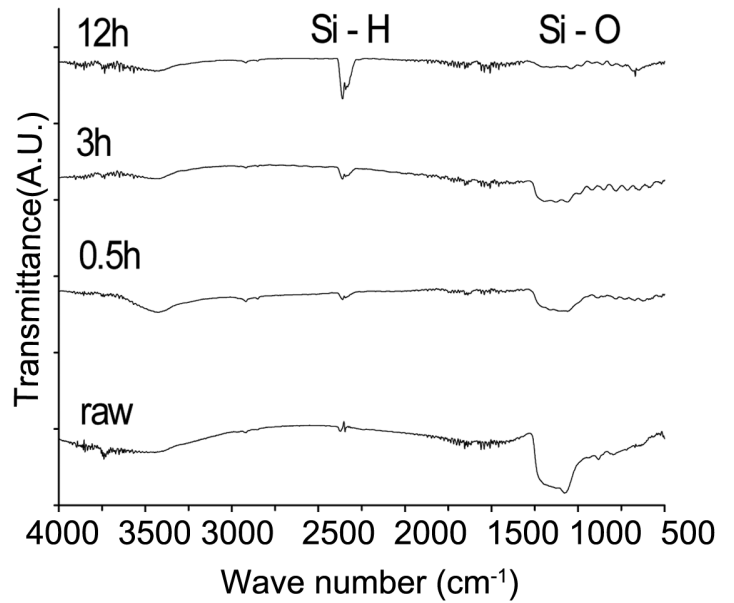

(a) Diethylene glycol

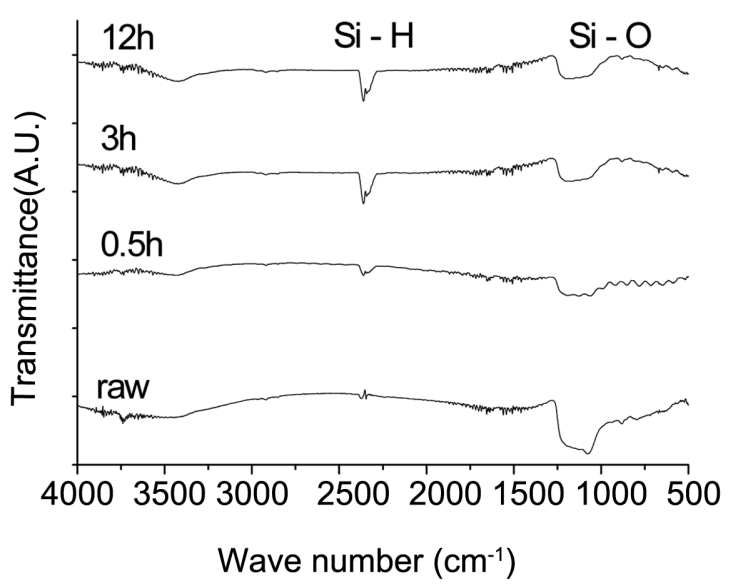

(b) Anhydrous ethanol

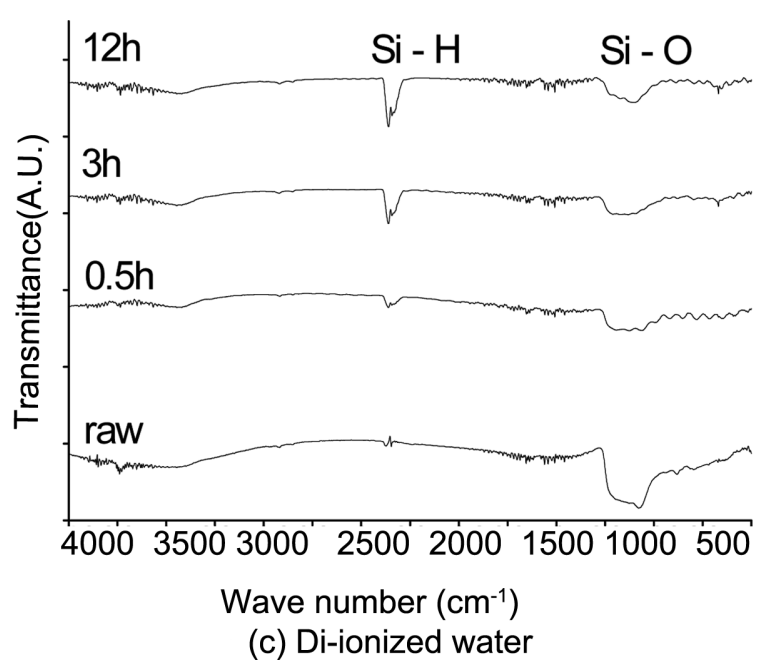

Fig. 5. FT-IR patterns of silicon powder varying with liquid medium and grinding time in wet-milling process. 
화가 많이 진행되었음을 확인할 수 있었다. 무수에탄올과 증류수를 액상매체로 사용했을 경우에는 분쇄가 진행될 수록 $\mathrm{Si}-\mathrm{O}$ 피크 변화는 크지 않았다. 하지만 디에틸렌글 리콜을 액상매체로 사용하였을 경우에는 분쇄가 진행됨 에 따라서 $\mathrm{Si}-\mathrm{O}$ 피크가 점차적으로 감소하여 실리콘 입 자표면의 산화방지에 가장 효과적일 것으로 판단되었다.

\section{Acknowledgment}

본 연구는 산업통상자원부 에너지기술개발사업 (2013 $\mathrm{T} 00100021)$ 과 교육과학기술부의 융합파이오니아 사업 (No. 2010-0019468)의 연구비 지원을 통하여 수행되었으며, 이 에 감사드립니다.

\section{REFERENCES}

1. Y. Huang, J. Q. Dai, Z. P. Xie, T. Ma, J. L. Yang, and J. T. $\mathrm{Ma}$, "Effect of Liquid Medium and Ball-milling on the Surface Group and Aqueous Dispersibility of $\mathrm{Si}_{3} \mathrm{~N}_{4}$ Powder," $J$. Eur. Ceram. Soc., 23 [6] 985-90 (2003).

2. H. El-Shall and P. Somasunderson, "Physico-Chemical Aspects of Grinding : A Review of Use of Additives," Pow- der Technol., 38 [3] 275-93 (1984).

3. I. J. Lin and A. Metzmager, "The Influence of the Environment on the Comminution of Quartz," AIME, 241 [12] 142-418 (1968).

4. X. G. Zhang, "Electrochemistry of Silicon and Its Oxide,"; pp. 116-30, Kluwer Academic Publishers, New York, 2004.

5. A. M. Nymark. "Oxidation of Silicon Powder in Humid Air," pp.1-122, in Master Thesis, Norwegian University, Trondheim, 2012.

6. S. B. Jeong, J. Y. Hyun, and Y. B Chae, "The Effect of Additives on Ultrafine Grinding of Talc(in Korean)," J. Kor. Soc. Geosys. Eng., 43 [2] 134-42 (2006).

7. S. S. Ibrahim, "Effect of Intensive Grinding on the Physicochemical Properties and Reactivity of Red Sea Phosphates," Fizykochemiczne Problemy Mineralurgii, 30 95106 (1996).

8. C. Yin, X. Wei, Y. Xiong, P. Zhou, G. Zhong, and L. Zhou, "Oxidation Behaviors of Dusts Generated in Different Cutting Processes of Silicon Ingots," Adv. Mat. Res., 463-464 669-73 (2012).

9. W. T. Kwon, S. R. Kim, Y. Kim, Y. J. Lee, J. Y. Won. T. K. Ko, and S. C. Oh, "Characterization of Silicon Kerf and the Effect of Grinding on the Synthesis of SiC Powder," Mater. Sci. Forum, 761 69-72 (2013). 